\title{
BM] Global Health Democratizing innovation through grass-roots entrepreneurship: lessons from efforts to address the opioid epidemic in the United States
}

\author{
Shriya Srinivasan (D) , ${ }^{1}$ Khalil B. Ramadi (D) , ${ }^{1}$ Andrea Ippolito, ${ }^{2}$ Rifat Atun (D) ${ }^{3}$
}

\begin{abstract}
To cite: Srinivasan S, Ramadi KB, Ippolito A, et al. Democratizing innovation through grass-roots entrepreneurship: lessons from efforts to address the opioid epidemic in the United States. BMJ Global Health 2019;4:e002079. doi:10.1136/ bmjgh-2019-002079
\end{abstract}

Handling editor Soumitra S Bhuyan

Received 16 October 2019 Revised 2 December 2019 Accepted 10 December 2019

\section{Check for updates}

(c) Author(s) (or their employer(s)) 2019. Re-use permitted under CC BY-NC. No commercial re-use. See rights and permissions. Published by BMJ.

${ }^{1}$ Health Sciences and Technology, Massachusetts Institute of Technology, Cambridge, Massachusetts, USA ${ }^{2}$ Engineering Management Program, Cornell University, Ithaca, New York, USA

${ }^{3}$ School of Public Health, Harvard University, Boston, Massachusetts, USA

Correspondence to Shriya Srinivasan shriyas@mit.edu

\section{ABSTRACT}

The nationwide opioid epidemic has substantially impacted economically-depressed regions in the USA. Eastern Appalachia has some of the lowest socioeconomic indicators in the USA and has suffered the highest rate of opioid-related fatality in 2016. Despite devoting considerable federal and state resources towards public health initiatives, the region continued to experience one of the highest death rates and sought alternative approaches to address the opioid crisis. Here, we describe a community-based co-creation initiative that convened diverse sectors and utilised design thinking principles to generate sustainable public health ventures towards addressing the opioid crisis. Participants of diverse backgrounds came together to attack key challenges and developed and implemented solutions, including a mobile application for naloxone delivery and exercise programs for high schools to promote healthy habits. Grassroots innovation efforts catalysed by the event strengthened community engagement and facilitated a sense of agency among participants. Through specific examples of initiatives that were launched, we provide evidence to encourage and highlight the value of healthcare innovation efforts in low-resource settings.

\section{THE CRISIS IN EASTERN KENTUCKY}

A nationwide opioid epidemic has become the leading cause of death for young adults in the USA. It caused over 70,230 deaths in 2017, ${ }^{1}$ surpassing death by motor vehicle accidents. ${ }^{2}$ Among the most severely affected states is Kentucky, which has experienced over 1480 overdose deaths (29.9 per 100 $000)$ in $2017,,^{3}$ the third-highest rate in the nation. ${ }^{1}$ Fentanyl abuse hit at an all-time high in 2016, as evidenced by 623 overdose cases in Kentucky alone. ${ }^{4}$ The situation worsened with an alarming increase in fatality rates from $34 \%$ in 2015 to $47 \%$ in $2016 .{ }^{5}$ Combating substance abuse has been especially challenging for citizens in this region, given the state of its healthcare infrastructure and

\section{Summary box}

- The Appalachian region of eastern Kentucky has been devastated by record numbers of fatalities due to the opioid crisis and experienced little relief from traditional public health efforts.

- A healthcare hackathon in 2016 catalysed grassroots healthcare innovation through its systematic design thinking process, yielding numerous mobile applications and community health programmes targeted at the local opioid epidemic.

- Democratising healthcare innovation efforts and bringing together diverse stakeholders early in the ideation process has the potential to generate solutions for large-scale public health challenges.

- Healthcare innovation events have been largely concentrated in resource-rich areas where public health issues are often better managed. However, the tenets of the systematic design thinking processes used in this co-creation initiative offers valuable benefits in low-resource settings as well, where grassroots innovation has great potential to address local public health crises. 


\section{Box 1 MIT hacking medicine}

\section{MIT Hacking Medicine}

- MIT HM is a student group which teaches entrepreneurship and innovation through workshops and hackathons to address healthcare challenges. ${ }^{17}$ MIT HM pioneered the 'healthcare hackathon' and has run over 200 hackathons in over 36 US cities and over 25 countries globally. Solutions ranging from mobile applications and public health programmes to software platforms and medical devices have emerged from these events, spurring over 45 companies.

\section{What is a hackathon?}

- Hackathons are co-creation events in which participants from diverse background work together in small groups (4-6 members) to ideate products or services to solve healthcare challenges. Over the 48 hours event, participants are led through a systematic design thinking process, which focuses on identifying root problems, analysing varied stakeholder interests, designing sustainable business models and prototyping solutions (17). Mentorship from subject matter experts is provided and iteration based on feedback is performed. Cash prizes and opportunities to partner with local incubators are awarded to support development of proposed solutions.

HM, Hacking Medicine; MIT, Massachusetts Institute of Technology.

expenditures amount to over US $\$ 3.85$ billion dollars per year-220\% higher than similar regions nationwide. ${ }^{10}$

The local government and health systems implemented several strategies since 2014 to mitigate the opioid and related public health crises. Efforts included policy changes to create smoke-free environments, hospital incentives for syringe exchanges and vaccination, and public health campaigns to educate youth and adults alike. ${ }^{11}$ The federal government had, among other initiatives, also dedicated special funding to developing distance learning programmes, implementing new prevention and treatment programmes, and increasing access to the overdose-reversal medicine, naloxone. ${ }^{12}$ Shaping Our Appalachian Region (SOAR), a governmental support organisation, designated 'substance use disorder' as a priority focus area in 2015 and partnered with the Centers for Disease Control and Prevention (CDC) to provide human resources and build capacity at the local level. Despite these initiatives, the worsening situation prompted the local government to seek a starkly novel approach to bring relief to the area. Thus, SOAR and the CDC partnered with the Massachusetts Institute of Technology's (MIT) Hacking Medicine (HM) group to co-localise the regional community and create technology-based solutions (box 1).

\section{DEMOCRATISING INNOVATION}

To address the public health issues facing Eastern Kentucky, MIT HM organised a healthcare hackathon (box 1) in October 2016 in Somerset, Kentucky. Traditionally, MIT HM primarily conducts hackathons in tech-savvy communities with large industry partners, clinical influence and plentiful private resources. In contrast, the Appalachian region demonstrated a limited entrepreneurial culture in public health, few multidisciplinary social ventures and a strong reliance on governmental funding and policy-driven change. ${ }^{13}$ The hackathon sought to modify this context by bringing together local citizens from diverse community sectors, having them prioritise their own challenges and develop strategies to address them. This flipped the existing paradigm and positioned citizens traditionally receiving aid to instead be the innovators and implementers, producing solutions for their community. The hackathon thus democratised the process of innovation by shifting the resources and onus of resolving the public challenge from the institutional level to the average citizen. We term this process as 'grassroots entrepreneurship'.

Teams were encouraged to think beyond medical products and devices, which are the traditional deliverables of hackathons, to create social enterprises and public health programme to overcome the opioid crisis, as well as underlying chronic disease or health infrastructure problems. Special cash prizes aimed at incentivising preventative solutions were crafted. For example, Passport Health Plan and WellCare Health Plan, two of Kentucky's managed care organisations, each sponsored a US $\$ 1000$ prize for novel pain management methods, one of the root causes of the opioid epidemic.

\section{HARNESSING COGNITIVE DIVERSITY}

A total of 138 participants and 38 high school students were selected through an application process from 24 counties in the SOAR region. Participants were selected to represent different disciplines, including academia, medicine, engineering, medical affairs administration, software, policy, insurance and health education (figure 1), thus creating an environment representative of various social, political and economic strata as well as varied interests, skill sets and experiences. Bringing these backgrounds into the same room enabled a balanced discussion that accounted for the varying needs and wants of each stakeholder. Most critically, all participants had first-hand knowledge of the opioid crisis, either through personal or family experience, priming them for the task. ${ }^{14}$ By relying on local resources with an enduser perspective, the hackathon facilitated the creation of contextually appropriate solutions.

\section{BRIDGING THE ACCESS GAP}

In rural communities such as those of Appalachia Kentucky, change is typically driven by top-down policy decisions, where space for discussion with end users is often limited. These sometimes lead to inefficient or ineffective programming due to improperly aligned needs and wants resulting from a lack of communication. ${ }^{15}$ The hackathon sought to bridge theses communication gaps between diverse stakeholders who rarely engaged in crosssectoral collaboration. Key leaders from the public sector, including Congressman Hal Rogers (fifth Congressional District), Douglas Lowy, MD, (Deputy Director, National 


\section{6 participants}
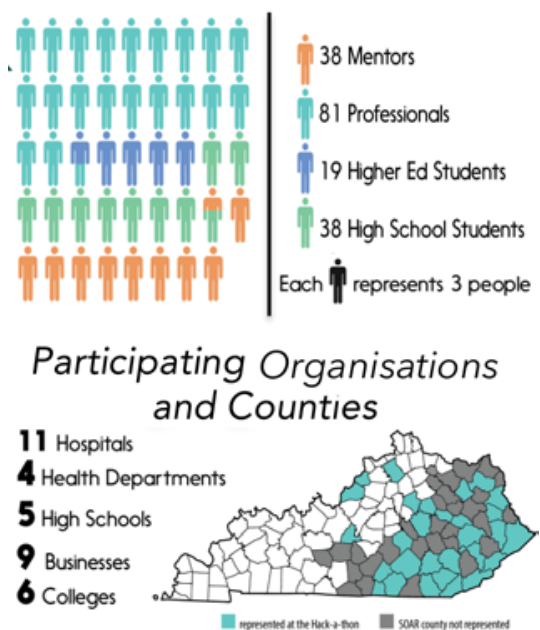

Mentor Expertise

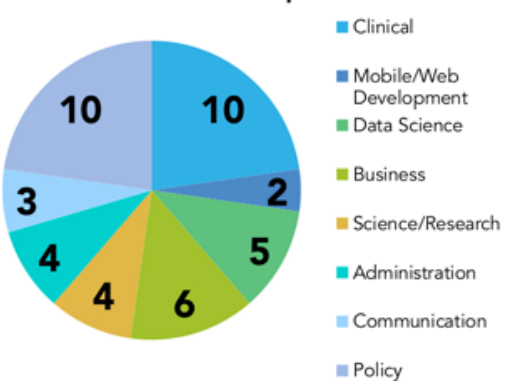

Figure 1 Graphical representation capturing the diversity of participants in the hackathon. Various organisations and over half of the counties in the SOAR sector attended. Mentors were able to provide expertise in a range of topics and connections to key organisations or leaders in their respective fields. SOAR, Shaping Our Appalachian Region.

Cancer Institute), Nora Volkow, MD, (Director, National Institute on Drug Abuse), and Tom Frieden, MD MPH, (Director, Centers for Disease Control and Prevention), were invited to attend and engage with participants. The hackathon also convened local leaders from universities, clinics and the Kentucky Valley Educational Cooperative (which serves 19 school districts in Eastern Kentucky) to discuss challenges and explore preventions and treatment solutions for the opioid crisis.

A barrier to the ideation and implementation of solutions from the community level was the lack of access to appropriate expertise and practical acumen. To address this barrier, the hackathon brought on-site 30 diverse mentors (figure 1) to guide participants in refining specific 'pain points' of the opioid crisis and conceptualising solutions. A subset of mentors from local medical centres and government provided feedback on the feasibility of solutions proposed.

\section{RESULTS OF OPEN INNOVATION}

A total of 19 teams were formed and created solutions in three broad areas: (A) education awareness/health promotion (seven projects), (B) relief/response (nine projects) and (C) chronic treatment (three projects). These solutions targeted the opioid epidemic as well as chronic diseases and social determinants that were linked causes. Notably, 7 of the 18 projects conceived at the hackathon have progressed and are being implemented in the region. Four mobile applications were created from this initiative and three projects won additional funding. Here, we highlight examples of initiatives launched from the hackathon:

\section{ODSave}

With an increasing rate of overdose incidents, local dispatches and emergency teams often lack sufficient capacity to respond to all situations. Moreover, many Kentucky 911 dispatches do not accept mobile calls. To mitigate long response times, alleviate an overburdened emergency response system and take advantage of the availability of qualified first responders, a mobile application called ODSave was created (figure 2). ODSave expands the network of responders by enabling anyone witnessing an overdose to send out an alert. Registered responders in the geographically proximal area can respondsimilar to ride-sharing services such as Uber. The service simultaneously notifies the emergency medical services (EMS) dispatch. The team creating ODSave comprised a drug counsellor, first responder, coder and pharmacist, each bringing critical perspectives to the project. Over the course of the hackathon, this team rapidly prototyped the application and validated feasibility assumptions through conversations with mentors. This team won second place at the event, proving the need and viability to funders, who then invested in the full development of the app. Following 2 years of research and development, the ODSave app is now available on the Google Play and Apple App Stores. It is currently being piloted in Pikeville municipality with registered users and will soon be made available to the public.

\section{Simple health 5-5-5}

Created by a team from Pikeville High School, 'Simple Health $5-5-5$ ' is a mobile application that encourages users to commit to a healthier lifestyle through peer networking and positive feedback for implementing good habits. The application motivates users to drink five glasses of water, eat five servings of fruits and vegetables each day, and walk for five minutes five times per day. This application also allows users to connect with friends or family to create a support system and motivate others. The team was awarded a cash prize and FitBits to jumpstart their project from Pikeville Medical Center. Students are actively using the app to motivate themselves and keep friends accountable to engage in healthy habits.

\section{Indoor walking track}

Another high school team implemented an indoor walking track in their high school to promote regular exercise and lower the barrier of finding a gym. This track 

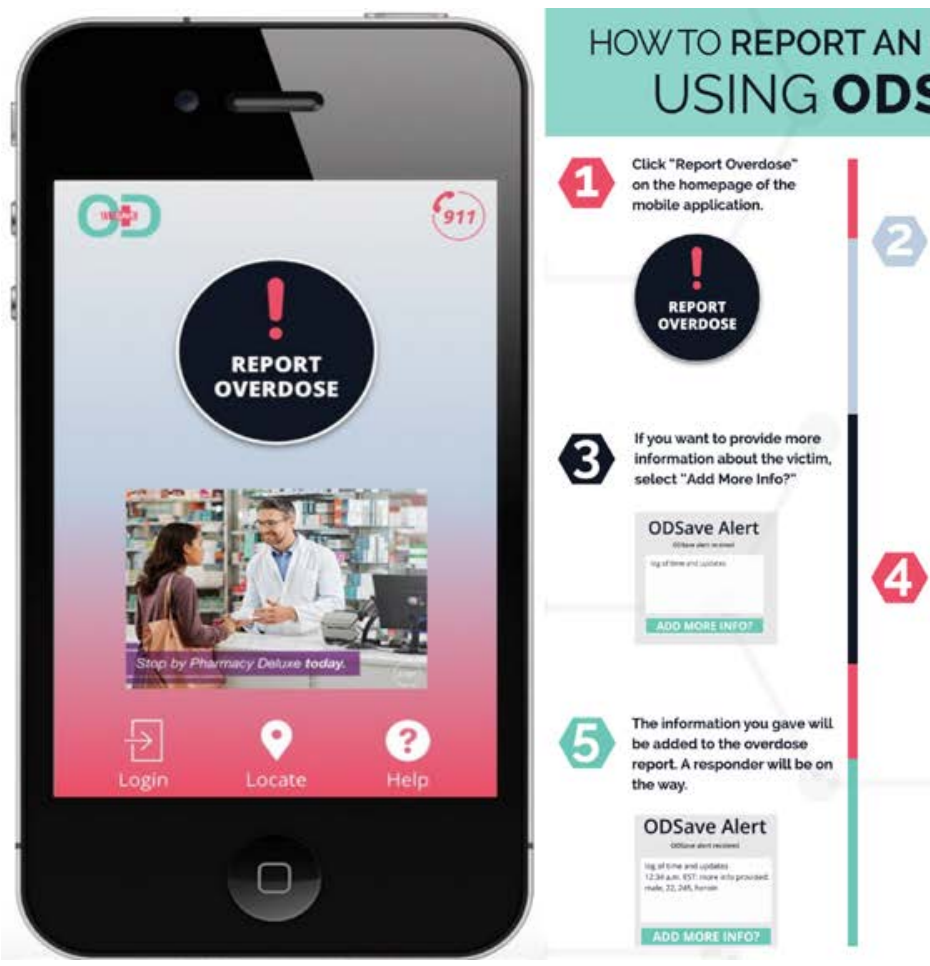

\section{OVERDOSE AVE}

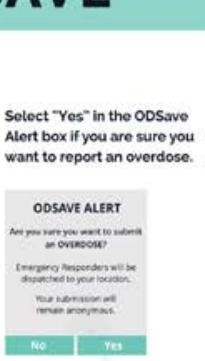

You can add any of the chordose roport seloct "Submit" when finished

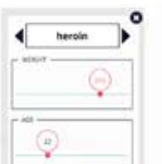

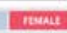

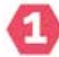

Select "Login" on the homepage of the mobile application
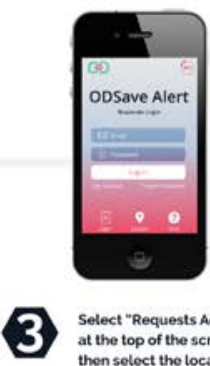

Select "Requests Accepted at the top of the screen, the accept the location the accepted request

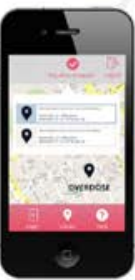

HOW RESPONDERS CAN ACCEPT AN OVERDOSE REPORT

Figure 2 Left: Display of main screen of the ODSave mobile application designed to create a rapid response naloxone delivery network. Middle: Flowchart describing the process by which overdoses can be reported anonymously using the application. Right: Workflow for emergency responders to view and request alerts for overdose cases.

is equipped with quick response codes that users can scan with an app to access a map, track their distance walked, $\log$ their participation and access information about the local area and tips on healthy habits. This team had also entered the 'Samsung Solve for Tomorrow' national contest and was selected as a state finalist. The walking track is now regularly used at the high school, promoting healthy habits among the students and teachers there.

\section{NObesity}

Apart from mobile applications, a number of community programmes also resulted from the hackathon. NObesity was one such preventative lifestyle-modification initiative, which aims to promote healthy activity and prevent obesity among school-age children through an afterschool activity programme. Following the hackathon, the team was approached by the University of Kentucky to partner and help develop the programme. A local 'Boys and Girls Club' is now engaged with NOBesity for implementation.

\section{A SHIFT IN THINKING}

The mobile applications and community programme that emerged from the hackathon provided concrete solutions to address the opioid crisis. More importantly, however, the hackathon encouraged a shift in the perception of health innovation and technology, empowering the average citizen to initiate change where she/he found it necessary. At the start of the hackathon-overwhelmed by the scope of the issue, limited resources and an ingrained mindset of bureaucracy-most participants felt that the opioid crisis was 'too big' a problem for individuals to take into their own hands. However, the hackathon imparted a systematic design thinking method for problem identification and analysis. Once broken into manageable pieces and supported by resources that could provide technical assistance, participants were able to envision solutions that were unrestricted to their professional silos. For many government officials, patients, clinicians and community members, this was their first foray into collaborative innovation. In follow-up interviews with participants, over $80 \%$ reported a change in their perspective with respect to the crisis at hand and their ability to form coalitions with hospitals and public health organisations. High school teachers reported positive changes in student attitude and health-related behaviour as a result of the hackathon. Teachers elaborated that the hackathon was a practical way to enable their students to think critically about problems in their local community, collaborate with their peers, practice creative thinking and implement their ideas. Organisers and local government officials reported that community empowerment and mobilisation were perhaps the most important outcomes of the hackathon.

This change in mindset has been previously characterised as a type of innovation itself and is commonly associated with cross-functional thinking and empathetic design through user-needs analyses. ${ }^{16}$ The more an organisation understands and practices 'innovation as a mindset', the better its members' interests will align and result in 
progress. ${ }^{16}$ The healthcare hackathon model strongly facilitates this process for small- and large-scale organisations. ${ }^{17} 18$

\section{SPREADING GRASSROOTS EFFORTS BEYOND THE HACKATHON}

Following the introduction of the hackathon model to the Eastern Kentucky ecosystem, local organisations started organising similar events. For example, the Kentucky Valley Educational Cooperative held a 'mini-hack' for three high school teams to tackle the opioid epidemic. This initiative garnered the support of the Kentucky Office of Excellence in Rural Health. During this event, one team developed a solution to decrease the stigma around substance abuse and help identify individuals in need of help. Through iteration, this project developed a mobile application called the 'Empty Chair'-representing the multitude of empty chairs left by the family members lost to opioid abuse. The app has increased awareness and lowered the barrier of access to information about this sensitive topic to youth in the region. The region's interest in hosting such events and nurturing these projects demonstrated the hackathon's ability to spur additional grassroots initiatives.

\section{DECENTRALISING RESPONSIBILITY TO EMPOWER GRASSROOTS INNOVATION}

As demonstrated in this case study, the healthcare hackathon model is adaptable to a broad range of entrepreneurial environments, policy constraints, disease areas and technological landscapes. Its core principles of (1) convening cognitive diversity, (2) using systematic problem identification and (3) iterative solution development were highly applicable to the opioid crisis in eastern Kentucky and yielded numerous programme that succeeded within the socioeconomic and political conditions of the region. By decentralising the responsibility of addressing the public health challenges from institutions into the hands of citizens, hackathons democratise decision-making and solution generation. Notably, aligning stakeholders and incorporating their perspectives early in the innovation process lead to more effective ideation and often lead to more successful outcomes. ${ }^{19} 20$

Hackathons have been effectively used elsewhere in the healthcare industry to improve community response. In 2016, the Department of Veterans Affairs (VA) created the 'VA Innovators Network', a programme modelled after Hacking Medicine. Using a similar framework as the hackathon model elaborated previously, the Innovators Network equipped VA employees with the best innovation tools to tangibly remagine the way the VA serves veterans and develops new ideas in collaboration with Veteran communities. To date, the programme has been launched at 33 VA Medical Centers and has witnessed high efficacy in resource-constrained settings facing public health crises. In VA-wide competitions, winning entries focused on building community partnerships to increase access to care for at-risk Veterans.
Other university-based frameworks such as the 5-day (Innovation to Impact) entrepreneurship course at Yale University for substance abuse researchers (http:// www.innovationtoimpact.com/) and Stanford's innovation course for mental health serve as a launchpad for academics and contribute to the educational ecosystem for healthcare entrepreneurship.

Whether it be community settings, universities or government-wide hospital systems, the design thinking approach has efficaciously driven change in resourceconstrained areas. $^{21} 22$ Thus, we advocate the more regular incorporation of grassroots innovation events into national and global public health initiatives, especially in low-income settings. With the declaration of the opioid epidemic, a public health emergency by the federal government in 2018, numerous private-sector and non-profit partners are coming together with the federal agencies to provide support and solutions. ${ }^{23}$ Providing an avenue for the average citizen to become a part of this initiative through hackathons, for example, may present a valuable opportunity to develop novel solutions, energise the community and even concurrently address issues of cultural boundaries. ${ }^{24}{ }^{25}$ The 'last mile of care', funding and incentives for reimbursement still pose major challenges to solving public health crises. Notwithstanding, performing grassroots innovation in low-resource settings can accelerate relief.

\section{CONCLUSIONS}

Innovation workshops and events have been largely concentrated in resource-rich and tech-rich areas, where public health issues are often better managed. Against the backdrop of a deadly opioid crisis in a lower-resource setting such as Kentucky, a hackathon provided the necessary catalysis to spur grassroots innovation efforts. The MIT HM design thinking methodology enabled systematic dissection of a complex problem into component parts that made the challenge approachable. As one of the participants stated, 'A renaissance does not happen from a top down approach. It happens from people understanding what they need, what skills they have, and working together with support systems to create what they need. And that's what the hackathon represented'. As we look to the future, we should consider availing similar strategies that democratise innovation and prioritise local knowledge to address public health challenges in lower-resource settings.

Twitter Rifat Atun @RifatAtun

Contributors SS: conducted this hackathon in 2016 and performed the analysis and writing of the manuscript. KR, Al and RA: contributed to writing and editing the manuscript.

Funding The authors have not declared a specific grant for this research from any funding agency in the public, commercial or not-for-profit sectors.

Competing interests None declared.

Patient consent for publication Not required.

Provenance and peer review Not commissioned; externally peer reviewed. 
Data availability statement All data relevant to the study are included in the article.

Open access This is an open access article distributed in accordance with the Creative Commons Attribution Non Commercial (CC BY-NC 4.0) license, which permits others to distribute, remix, adapt, build upon this work non-commercially, and license their derivative works on different terms, provided the original work is properly cited, appropriate credit is given, any changes made indicated, and the use is non-commercial. See: http://creativecommons.org/licenses/by-nc/4.0/.

\section{ORCID iDs}

Shriya Srinivasan http://orcid.org/0000-0002-2508-1324

Khalil B. Ramadi http://orcid.org/0000-0002-5864-2386

Rifat Atun http://orcid.org/0000-0002-1531-5983

\section{REFERENCES}

1 CDC Injury Center. Drug overdose death data. Drug overdose, 2017. Available: https://www.cdc.gov/drugoverdose/data/statedeaths.html [Accessed 17 Dec 2017].

2 Kolodny A. The opioid epidemic in 6 charts. The conversation. Available: http://theconversation.com/the-opioid-epidemic-in-6charts-81601 [Accessed 11 Mar 2018]

3 National Institute on Drug Abuse. Overdose death rates, 2017. Available: https://www.drugabuse.gov/related-topics/trendsstatistics/overdose-death-rates [Accessed 30 Dec 2017].

4 Clinicpharmacy. Fentanyl drives rise in Opioid-Linked deaths in U.S. Available: https://clinicpharmacyrx.com/greenville/article.php?id= 726120/ [Accessed 17 Dec 2017].

5 Barlas S. U.S. and states ramp up response to opioid crisis: regulatory, legislative, and legal tools brought to bear. $P T$ 2017;42:569-92.

6 U.S. Census Bureau. QuickFacts: Kentucky. Available: https://www. census.gov/quickfacts/fact/table/KY/PST045216 [Accessed 12 Mar 2018].

7 May 2017 OES state occupational employment and wage estimates Kentucky. Available: https://www.bls.gov/oes/2017/may/oes_ky. $\mathrm{htm} \# 00-0000$ [Accessed 14 Dec 2018].

8 Centers for Disease Control and Prevention. Stats of the state of Kentucky. Available: https://www.cdc.gov/nchs/pressroom/states/ kentucky.htm [Accessed 14 Dec 2018].

9 Appalachian Regional Commission. Health disparities in Appalachia Available: https://www.arc.gov/research/researchreportdetails.asp? REPORT_ID=138 [Accessed 14 Dec 2018].
10 Kentucky diabetes fact sheet. Ky Public Health 2016.

11 Drug Control Policy. Kentucky agency for substance abuse policy. Available: https://odcp.ky.gov/Pages/Agency-for-Substance-AbusePolicy.aspx [Accessed 14 Dec 2018].

12 The White House. Fact sheet: Obama administration Announces prescription opioid and heroin epidemic awareness week, 2016. Available: https://obamawhitehouse.archives.gov/the-pressoffice/2016/09/19/fact-sheet-obama-administration-announcesprescription-opioid-and-heroin [Accessed 11 Nov 2019].

13 Behringer B, Friedell GH. Appalachia: where place matters in health. Prev Chronic Dis 2006;3:A113.

14 Sinha SR, Barry M. Health technologies and innovation in the global health arena. N Engl J Med 2011;365:779-82.

15 Herzlinger RE. Why innovation in health care is so hard. Harv Bus Rev 2006;84:58-156.

16 Kahn KB. Understanding innovation. Bus Horiz 2018;61:453-60.

17 Gubin TA, lyer HP, Liew SN, et al. A systems approach to healthcare innovation using the MIT Hacking medicine model. Cell Syst 2017;5:6-10.

18 Olson KR, Walsh M, Garg P, et al. Health hackathons: theatre or substance? A survey assessment of outcomes from healthcarefocused hackathons in three countries. BMJ Innov 2017;3:37-44.

19 Lee J, Min J, Lee H. The effect of organizational structure on open innovation: a quadratic equation. Procedia Comput Sci 2016;91:492-501.

20 Liu Y, Lv D, Ying Y, et al. Improvisation for innovation: the contingent role of resource and structural factors in explaining innovation capability. Technovation 2018;74-75:32-41.

21 DePasse JW, Carroll R, Ippolito A, et al. Less noise, more hacking: how to deploy principles from MIT's hacking medicine to accelerate health care. Int J Technol Assess Health Care 2014;30:260-4.

22 Mantzavinou A, Ranger BJ, Gudapakkam S. Health hackathons drive affordable medical technology innovation through community engagement. In: Hostettler S, Najih Besson S, Bolay J-C, eds. Technologies for development. Cham: Springer International Publishing, 2018: 87-95.

23 White House. A year of historic action to combat the opioid crisis, 2018. Available: https://www.whitehouse.gov/articles/year-historicaction-combat-opioid-crisis/ [Accessed 10 Nov 2019].

24 Ramadi K B, Srinivasan S, Atun R. Health diplomacy through health entrepreneurship: using hackathons to address Palestinian-Israeli health concerns. BMJ Glob Health 2019;4:e001548.

25 Ramadi KB, Atun R. Health in the Arab world. Lancet 2019;394:826-7. 